\title{
Pumped-Storage Hydroelectric Power Station Location in Tenerife Island
}

\author{
M.Martínez, J.Romero, A.Pulido F.Deniz and J.C.Quintana \\ Department of Electrical Engineering \\ Las Palmas de Gran Canaria University \\ Campus of Tafira - Edif. Ingenierías, 37017 Gran Canaria (Spain) \\ Phone:+0034 928 451987, e-mail: miguel.martinez@ulpgc.es, antonio.pulido@ulpgc.es
}

\begin{abstract}
The best site for a pumped storage hydroelectric power station in the Tenerife island has been find, to be later sized and simulated in the software Homer, in order to be able to observe its effect on the insular electrical system, allowing the inclusion of more renewable generation.
\end{abstract}

\section{Key words}

Generation planning, location, pumped storage, production simulation, dimensioning.

\section{Introduction}

The Tenerife island currently has an electricity system very dependent on oil, in 2014 the energy generated by oil was 3,278.8 GWh, and in the same period, the renewable production was $271.4 \mathrm{GWh}$, the $7.6 \%$ [1]. The island has high wind and sun values. With an average value of $2000 \mathrm{~h}$ / year of production of all its wind farms, with 4,500 h / year being the most efficient farm value.

For photovoltaic energy, there is an average production value of $1,647 \mathrm{~h} /$ year [1].

At present, it has an installed power of:

- Photovoltaic $\quad 115,076 \mathrm{~kW}$

- wind power $\quad 36,680 \mathrm{~kW}$

In the near future we want to strongly increase the implementation of renewable generation to reduce the heavy dependence on oil, and converge on the European goal of $20 \%$ of primary renewable energy in the year 2,020 .

Since the two strong renewable energies on the island are stochastic, they require the implementation of a storage device that helps match the generation with the demand, as well as the dynamic control of the grid parameters. For ecological and simple, and given the great differences of high existing on the island, it is necessary to look for a site for a Pumped Storage Power Station (PSPS).

For this purpose, an analysis of the long-term estimations of the long-term electricity demand carried out by official organization [2] has been carried out, in spite of making an own estimation.

$2020 \quad 2025$
- Own (Energy/year)
$3,734 \mathrm{GWh}$
3,880 GWh
- Planing:
$3,698 \mathrm{GWh}$
- Own (Peak/year): 632 MW
$654 \mathrm{MW}$

· Planing: $\quad 629 \mathrm{MW}$

\section{Process}

In order to minimize a possible economic investment, and since in the neighboring island (Gran Canaria), it has a project where the two reservoirs existed previously to the Project [3]. On the island of El Hierro, a natural volcanic hole has been used to avoid excavation of the upper pond [4].

It has been evaluated to perform the search in the following order.

- Existing ponds (EP-EP): Take advantage of existing infrastructure, upper and lower. These ponds will be valued near and with an important difference of high, up of $300 \mathrm{~m}$.

- Existing pond-New pond (EP-NP): Take advantage of existing infrastructures and locate a new infrastructure, either as upper or lower pond. They will look for those ponds near a steep slope, with the possibility of realizing a pond near the end of it.

- New Pond-New Pond (NP-NP): Location of two new infrastructures, nearby and in an area of steep slopes, with the possibility of building big ponds at both ends.

- New Pond-Ocean (NP-O): Completion of a new pond and take advantage of the sea as the lower pond. It will be avoided to enter in land to realize this installation, due to the repercussion that could have a leak in the pond, affecting to the groundwater.

In order to find a suitable location to possible pond, in addition to maximizing the storable energy, achieving an important difference of high, and possibility of making a large pond. All this without great distance between them, for which the inclines have been analyzed. Territorial and environmental considerations have been introduced. This excludes those places where their territorial use is one to be maintained, whether urban, industrial or agricultural. It's not good solution destroy part of cities, nor industrial polygons. In addition, the high food dependence of the island, would not allow the loss of productive agricultural land, having reduced food production/inhabitant in the Canary Islands by more than $30 \%$ in the last decade [5]. It has also been excluded those places where it could increase the risk of 
catastrophe, due to a break in the proposed pond over a city.

On the other hand in Tenerife, $48.6 \%$ of the ground is protected, so we should try to preserve it, as far as possible, and not harm the natural values existing on the island [5].

Only existing ponds or dams with a capacity of more than 50,000 m3 have been considered, nowdays counting 41 reservoirs of this type [6], see Fig.1.

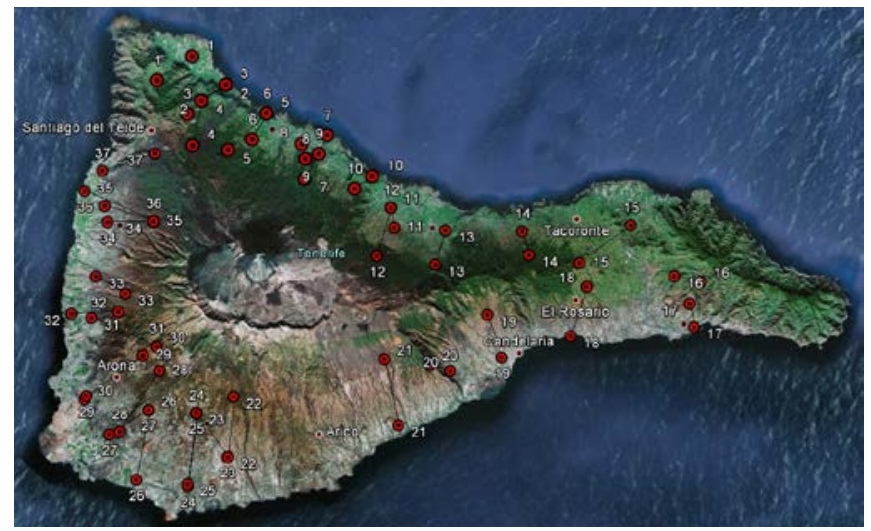

Fig. 1 Existing water reserves

Of all the possibilities was analyzed, the distance to the great centers of electric consumption in the island, the distance to the HV grid, the economic activity developed in that territory, environmental value affected, distance to coast of the lower reservoir, or possible feeding of fresh water to the System, available jump, existing roads accesses and slope, Fig 2,3.

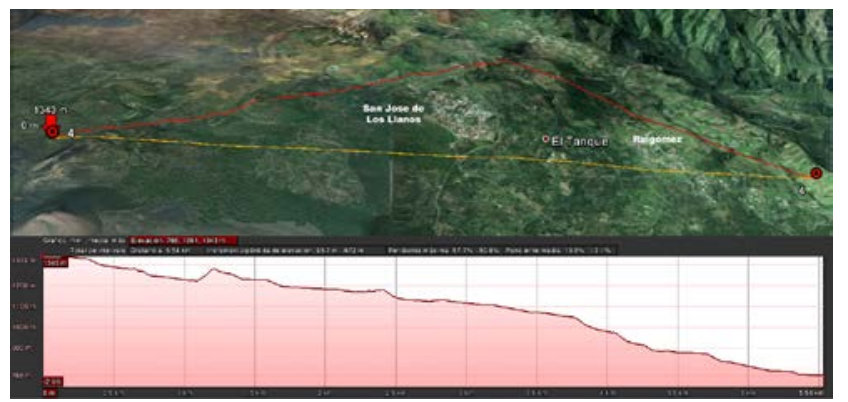

Fig. 2 Existing slope beteween two ponds

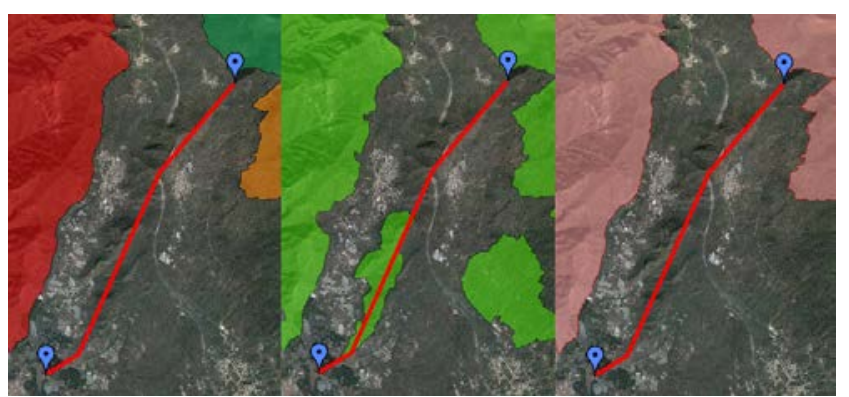

Fig. 3 Affections over environmental reserves

After making a table, valuing all these aspects. The best valued proposal has resulted, Fig.4.

- Lower pond, new created.

- Type: Waterproofed reservoir

- Water height: $15 \mathrm{~m}$

- Reservoir volume: 527,013 m³

- Maximum water level: $248 \mathrm{~m}$
• UTM: X 361,323 Y 3,131,376

- Upper pond, new created.

- Type: Waterproofed reservoir

- Water height: $15 \mathrm{~m}$

- Reservoir volume: 568,213 $\mathrm{m}^{3}$

- Maximum water level: 1,092 m

- UTM: X 359,199 Y 3,130,650

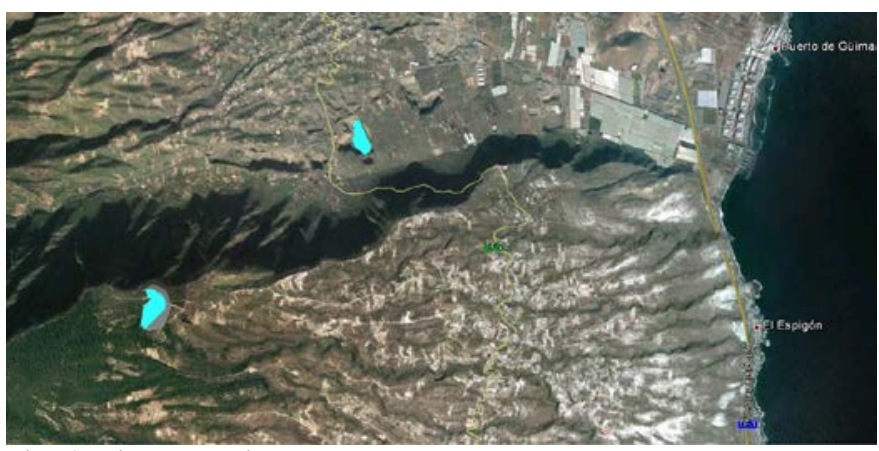

Fig. 4 Winer Location

The distance from the lower pond to the electricity transmission line on the island, $220 \mathrm{kV} \mathrm{HV}$, is $700 \mathrm{~m}$ to the existing line between the two existing thermal Power Stations.

The dimensioning indicated in the planning [2] has been used, however, an optimal dimensioning has been carried out to take advantage of the renewable generation, not from the point of view of the inverter, but considering the perspective of the electrical system [7].

The ponds may be filled by purified water by means of a nearby pipeline, or by a new desalination plant, the distance to coast is 3,447 $\mathrm{m}$ to the lower pond.

The proposed dimensioning would be:

- Three two-stage reversible units in Yang Yang

- Jump $844 \mathrm{~m}$

- Total Power of 3 x $60 \mathrm{MW}$

- Stored Energy: 1,158.36 MWh

- Daily duty cycle: 5 hours and 32 minutes at maximum generation

\section{Simulation of the electrical system}

The simulation of the current electrical system and the electrical system with the proposed PSPS will be carried out, and new renewable generation [8].

For which the software Homer has been used [9]. The hourly demand for the year 2014 has been introduced, multiplied by the growth forecast for the year 2,020. Whereas it will retain the shape of the current demand curve.

A. With the nowaday generation system in 2,020

- Total production (MWh /year) 3,735,214.53

- Consumption (MWh /year) 3,734,204.86

- Excess energy (MWh /year) 1,009.67

- Electric load not covered (MWh / year) 0.014

- Storage capacity (MWh) 0

It is observed that:

- The planning forecasts for generation of renewable origin have not been met.

- The energy must be produced at the moment it is going to be consumed. 
- Necessary balance between production and consumption at every moment.

- The thermal generation (combined cycle, gas turbines and diesel generator) must be the one that regulates the grid, with the consequent loss of performance and efficiency.

B. With PSPS and $a$ wind power increment of 2,020 Assuming an increase of the wind power, by means of 78 new wind turbines of the model FL2,500 / 100 of

Fuhrlander.

The PSPS has been modeled as a battery of:

- Nominal capacity (Ah) 17,550.9

- Rated voltage $(\mathrm{kV})$

66

- Efficiency\%

- Maximum discharge intensity (A) 2,727.27

With these extensions the results of the simulation are:

- Total production (MWh / year) 3,748,152.75

- Consumption (MWh / year) 3,734,204.86

- Excess energy (MWh / year) 13,947.89

- Electric load not covered (MWh / year) 0.0024

- Storage capacity (MWh) 1,158.36

Excess energy means generating $0.40 \%$ more annual than necessary.

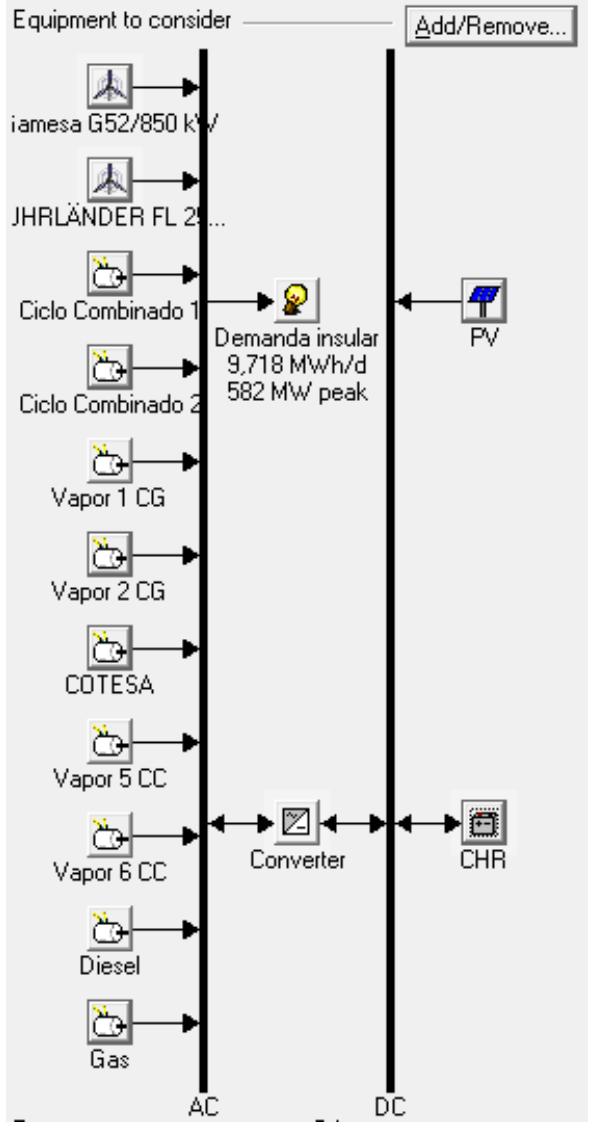

Fig 5. The proposed electrical scheme

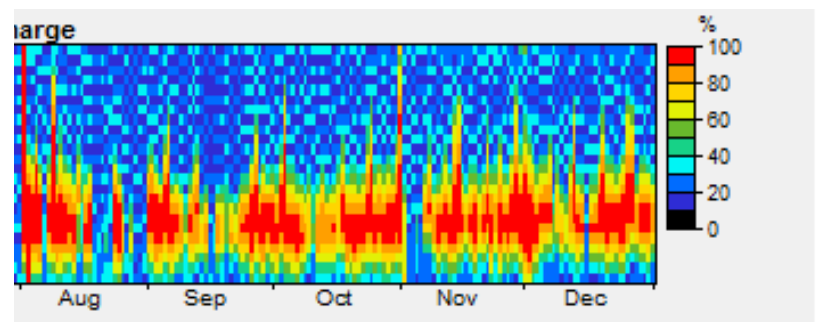

Fig. 6 Annual evolution Energy in PSPS

\section{Conclusion}

- The demand curve would be regulated, when pumping during the night.

- It would improve the efficiency of the thermal generation, reducing the oil consumption and the emission of contaminants.

- Generation of renewable origin would be better regulated.

- It would not be necessary to generate at the time it is going to be consumed.

- It improves the use renewable, since in periods of low demand and has to disconnect part of the stochastic generation. As this can't contribute more than $40 \%$ of the total generation, at no time without endangering the stability of the system.

- The possible pumping of the PSPS would allow the operation of more renewable in periods of high resource and low demand.

- Reducing the greenhouse effect, by allowing for greater renewable penetration, includes some considerations difficult to assess economically [10].

- The economic effects of emission reductions and potential subsidies have not been considered, so the PayBack is 16,4 years and TIR $8 \%$.

\section{References}

[1] Anuario Energético de Canarias 2014. http://www.gobiernodecanarias.org/energia/

[2] Plan de Desarrollo de la Red de Transporte de Energía Eléctrica 2015-2020. http://www.minetad.gob.es/energia/ planificacion/Planificacionelectricidadygas/desarrollo20152020

[3] Padrón, S., Medina, J. F., \& Rodríguez, A. (2011). Analysis of a pumped storage system to increase the penetration level of renewable energy in isolated power systems. Gran Canaria: a case study. Energy, 36(12), 6753-6762.

[4] Bueno, C., \& Carta, J. A. (2005). Technical-economic analysis of wind-powered pumped hydrostorage systems. Part II: model application to the island of El Hierro. Solar energy, 78(3), 396-405.

[5] http://www.gobiernodecanarias.org/istac/

[6] http://www.planhidrologicodetenerife.org

[7] Plan de Desarrollo de la Red de Transporte de Energía Eléctrica 2015-2020. http://www.minetad.gob.es/energia/ planificacion/Planificacionelectricidadygas/desarrollo20152020

[7] Papaefthymiou, S. V., \& Papathanassiou, S. A. (2014). Optimum sizing of wind-pumped-storage hybrid power stations in island systems. Renewable Energy, 64, 187-196.

[8] Caralis, G., Papantonis, D., \& Zervos, A. (2012). The role of pumped storage systems towards the large scale wind integration in the Greek power supply system. Renewable and Sustainable Energy Reviews, 16(5), 2558-2565.

[9] http://www.homerenergy.com/

[10] Zhang, N., Kang, C., Kirschen, D. S., Xia, Q., Xi, W., Huang, J., \& Zhang, Q. (2013). Planning pumped storage capacity for wind power integration. IEEE Transactions on Sustainable Energy, 4(2), 393-401. 